\title{
EFEITO DA COBERTURA DO SOLO COM RESÍDUOS DE AVEIA PRETA NAS ETAPAS DO CICLO DE VIDA DO CAPIM-MARMELADA ${ }^{1}$
}

\author{
GIOVANI THEISEN ${ }^{2}$ e RIBAS A. VIDAL ${ }^{3}$
}

\section{RESUMO}

Conduziu-se um experimento na Estação Experimental Agronômica da UFRGS, em Eldorado do Sul, RS, em 1996/97, com o objetivo de caracterizar as etapas do ciclo de vida de papuã (Brachiaria plantaginea), desenvolvendo-se sob solo com níveis de 0 a 10,5 t/ha de resíduos de aveia preta (Avena strigosa). Maior concentração de sementes de papuã foi observada nas camadas superficiais do solo. A cobertura vegetal influenciou a emergência de papuã, constatando-se 4,5 e $0,08 \%$ de germinação do banco de sementes para níveis de resíduos 0 e 10,5 t/ha, respectivamente. Verificou-se elevada mortalidade de plântulas em qualquer nível de cobertura sobre o solo. $\mathrm{O}$ aumento da cobertura do solo diminuiu o número de plantas adultas, aumentando a matéria seca por indivíduo, mas, mantendo a biomassa por área. Estes resultados indicam que as etapas do ciclo de vida de Brachiaria plantaginea são afetadas pela presença de resíduos vegetais na superfície do solo, sendo a germinação de sementes e emergência de plântulas as fases mais sensível aos tratamentos testados.

Palavras-chave: Avena strigosa, conservação do solo, planta daninha, plantio direto, resíduos vegetais.

\section{ABSTRACT}

\section{Alexandergrass life-cycle is affected by black oat residues on the soil surface}

One experiment was conducted at the Universidade Federal do Rio Grande do Sul, in Eldorado do Sul, RS, Brazil, during 1996/97, to characterize the life-cycle of alexandergrass (Brachiaria plantaginea) when developed under several levels (0 to $10,5 \mathrm{t} / \mathrm{ha}$ ) of black oat (Avena strigosa) residues on the soil surface. Weed seeds were more frequent at the upper layers of the soil profile. The crop residues affected alexandergrass seedling emergence, with 4,5 and $0,08 \%$ seed germination from the seedbank, for residue levels of 0 and 10,5 t/ha, respectively. High seedling mortality was observed at all crop residue levels. Increasing the levels of residues reduced the density of adult plants and increased plant dry weight, but maintained biomass per area. The results demonstrate that the phases of alexandergrass life-cycle are affected by the level of crop residues on the soil surface, and that the seed germination and seedling emergence are the phases most sensitive to the treatments tested.

Key words: Brachiaria plantaginea, Avena strigosa, no-till, soil conservation, crop residues, weed.

\footnotetext{
${ }^{1}$ Recebido para publicação em 28/05/98 e na forma revisada em 25/08/98.

${ }^{2}$ Eng. Agr., M.Sc. Faculdade de Agronomia da UFRGS. Av. Bento Gonçalves 7712, Porto Alegre/RS. CEP: 90001-970. (gtheisen@pro.via-rs.com.br).

${ }^{3}$ Eng. Agr., Ph.D., Professor da UFRGS, Pesquisador do CNPq. (vidal@if1.if.ufrgs.br).
} 


\section{INTRODUÇÃO}

O ciclo de vida de plantas daninhas pode ser subdividido em etapas distintas, tais como germinação, sobrevivência de plantas e produção de sementes, que são conectadas por processos fisiológicos e ecológicos (Fernandez-Quintanilla, 1988). A divisão do ciclo de vida das plantas em etapas permite quantificar os ganhos e perdas em cada fase e, assim, investigar os fatores regulando sua variação, possibilitando adotar medidas adequadas para o controle de plantas daninhas a longo prazo (Cousens \& Mortimer, 1995).

A germinação é um processo chave na organização e dinâmica das espécies, sendo muito sensível à cobertura do solo. Resíduos vegetais na superfície do solo alteram a umidade, luminosidade e temperatura do solo, principais elementos no controle da dormência e germinação de sementes (Cousens \& Mortimer, 1995). A cobertura do solo também pode prejudicar as plântulas em desenvolvimento, pela barreira física, causando o estiolamento das plantas e tornando-as suscetíveis aos danos mecânicos. Pode atuar, ainda, por efeitos químicos, como alterações na relação $\mathrm{C} / \mathrm{N}$ do solo e alelopatia. Finalmente, pode favorecer o desenvolvimento de insetos e fungos, muitos dos quais são predadores e hospedeiros de sementes e parte aérea das plantas daninhas. Porém, aquelas plantas que sobrevivem às dificuldades iniciais de estabelecimento quando o solo for protegido com camada espessa de resíduos vegetais, geralmente são beneficiadas pela baixa população, cabendolhes uma grande porção dos recursos do ambiente, favorecendo o seu desenvolvimento e produção de sementes.

Os processos envolvidos na regulação da densidade populacional das plantas são vários. Podem-se destacar os fatores como os elementos edáficos e climáticos, além das interações entre indivíduos, denominados de fatores dependentes de densidade. A mortalidade, tamanho e produção de sementes de plantas em competição são exemplos destes fatores (Cousens \& Mortimer, 1995).

Entre as plantas daninhas presentes nas culturas de verão, o papuã (Brachiaria plantaginea) (BRAPL) é a gramínea de maior incidência, encontrando-se presente na maioria das áreas do Planalto do Rio Grande do Sul (Bianchi, 1996). De maneira geral, essa invasora está presente na maioria das áreas com culturas de verão em diversos locais no Brasil, causando prejuízos consideráveis ao rendimento e qualidade da produção (Kissmann, 1991; Fleck, 1996). Na cultura da soja, por exemplo, B. plantaginea é responsável por perdas de até $82 \%$ na produção de grãos (Fleck, 1996).

Assim, o objetivo deste trabalho foi caracterizar e quantificar as etapas do ciclo de vida de BRAPL, desenvolvendo-se em solo com vários níveis de cobertura vegetal sobre sua superfície.

\section{MATERIAL E MÉTODOS}

O experimento foi conduzido no município de Eldorado do Sul, RS, em solo Podzólico Vermelho-Escuro distrófico (PAULEDULT) (Espírito Santo, 1988). Os tratamentos testados foram cinco níveis de palha de aveia-preta (Avena strigosa) $(0 ; 2,6 ; 5,2 ; 7,8$ e $10,5 \mathrm{t} / \mathrm{ha}$ ), a qual foi dessecada, cortada e colocada na superfície do solo de forma a manter como tratamentos os níveis de matéria seca. Utilizou-se delineamento em blocos casualizados, com quatro repetições. Cada parcela consistiu de área de $8 \mathrm{~m}^{2}$ (4 x $2 \mathrm{~m}$ ), delimitando-se uma área central de $1 \mathrm{~m}^{2},(1 \times 1 \mathrm{~m})$ onde se executaram as avaliações.

Antes da instalação do experimento avaliou-se o banco de sementes do solo nas profundidades de 0 a 3,3 a 6 e 6 a $9 \mathrm{~cm}$, utilizando-se trado metálico com $10 \mathrm{~cm}$ de diâmetro, introduzido verticalmente no solo em oito locais da área experimental. As sementes foram separadas do solo com auxílio de água e peneiras, sendo contadas manualmente. 
Aos 14, 27, 31, 48, 55, 73, 82 e 97 dias após a colocação da palha sobre o solo (DAT) fez-se a contagem das plantas de BRAPL $/ \mathrm{m}^{2}$. A matéria seca das plantas foi determinada coletando-se o material remanescente após 97 DAT, o qual foi seco a $60^{\circ} \mathrm{C}$ por 48 horas, e pesado posteriormente.

Todos os dados foram submetidos à análise de variância, complementados com testes de comparação de médias (Tukey a 5\%) e análise de regressão, segundo os modelos propostos por Zullo Jr. \& Arruda (1986).

\section{RESULTADOS E DISCUSSÃO}

O número de propágulos compondo o banco de sementes de BRAPL variou no perfil do solo. Observaram-se populações de 25.127, 6.430 e 3.162 sementes $/ \mathrm{m}^{2}$, para profundidades de 0 a 3 ,
3 a 6 e 6 a 9 centímetros, respectivamente. A presença de grande parte das sementes próximo à superfície é típica de sistemas agrícolas com pouco revolvimento do solo (Buhler \& Oplinger, 1990; Almeida, 1991; Rüedell, 1995; Radosevich et al., 1997). Esta característica pode interferir na comunidade de plantas daninhas, influenciando a dormência, a germinação e a mortalidade das sementes.

Menores níveis de cobertura do solo proporcionaram maiores percentuais de emergência de BRAPL (Tabela 1). Constatou-se que pequena percentagem do banco de sementes do solo $(4,47 \%)$ germinou e chegou à fase de plântula e de planta adulta (Tabela 2), caracterizando a estratégia da espécie de manter a maior parte de sua população na forma "passiva" (Radosevich et al., 1997), garantindo a emergência de plantas nos anos subseqüentes.

TABELA 1. Emergência de sementes de Brachiaria plantaginea, durante o ciclo de vida de 0 a 97 DAT $^{1}$, em cinco níveis de cobertura vegetal sobre o solo. EEA/UFRGS, Eldorado do Sul, RS, 1997.

\begin{tabular}{cc}
\hline Cobertura vegetal (t/ha) & Emergência $^{2}(\%)$ \\
\hline 0,0 & 4,47 \\
2,6 & 1,23 \\
5,4 & 0,18 \\
7,8 & 0,29 \\
10,5 & 0,08 \\
\hline
\end{tabular}

${ }^{1}$ Dias após o manejo da palha sobre o solo

${ }^{2}$ Banco de sementes com 34.719 sementes $/ \mathrm{m}^{2}$, até $9 \mathrm{~cm}$.

TABELA 2. Evolução da população de Brachiaria plantaginea durante o ciclo de vida entre 14 e 97 DAT $^{1}$, em cinco níveis de cobertura vegetal sobre o solo. EEA/UFRGS, Eldorado do Sul, RS, 1997.

\begin{tabular}{crrrrrrrr}
\hline Palha & \multicolumn{7}{c}{ População (plantas/m $\left.{ }^{2}\right)$} \\
& 14 & 27 & 31 & 48 & 55 & 73 & 82 & 97 \\
\cline { 2 - 9 }$(\mathrm{t} / \mathrm{ha})$ & 1401 & 1217 & 1104 & 944 & 820 & 972 & 871 & 595 \\
\hline 0,0 & 203 & 128 & 291 & 351 & 277 & 126 & 111 & 74 \\
2,6 & 56 & 41 & 30 & 34 & 36 & 26 & 25 & 22 \\
5,2 & 74 & 60 & 49 & 51 & 62 & 39 & 54 & 46 \\
7,8 & 25 & 11 & 9 & 12 & 9 & 9 & 8 & 8 \\
10,5 & & & & & & &
\end{tabular}

${ }^{1}$ Dias após o manejo da palha sobre o solo. 
Especula-se que a maior parte das plantas emergidas seja oriunda de sementes situadas na camada superficial do solo, devido a, pelo menos, dois motivos. Primeiro, pelo elevado número de sementes observado nos primeiros $3 \mathrm{~cm}$ de solo e, segundo, pela maior flutuação térmica diária ocorrente na superfície do solo do que em camadas profundas (Vidal, 1995; Salton \& Mielnickzuk, 1995), um dos principais requisitos ambientais à germinação de BRAPL (Carollo et al., 1997).

$\mathrm{O}$ reduzido número de plantas estabelecido em solo com o maior nível de cobertura vegetal (Tabela 2) pode ser devido a diversas causas: fatores físicos, tais como a palha, impedem a penetração da radiação solar no solo e diminuem a amplitude térmica e hídrica do solo (Bragagnolo \& Mielnickzuk, 1990), atuando como barreira física ao crescimento normal das plântulas (Vidal, 1995). Fatores químicos como substâncias alelopáticas liberadas por resíduos vegetais (Putnam et al., 1983), ou mudanças na relação $\mathrm{C} / \mathrm{N}$ e níveis de nitrato no solo; e fatores biológicos, como insetos e patógenos encontrados na camada de palha (Kremer \& Spencer, 1989; Kremer, 1998). De fato, nos tratamentos com nível de 10,5 t/ha de palha (Tabela 2), observaram-se plântulas estioladas, com hipocótilo alongado, superior a $3,5 \mathrm{~cm}$, com o nó da coroa posicionado acima da camada de palha. Tais plantas tornam-se altamente sensíveis aos danos mecânicos e suscetíveis ao ataque de predadores.

Quanto ao efeito sobre a emergência verificou-se (Figura 1) que para maiores níveis de cobertura sobre a superfície do solo com resíduos de aveia diminuíram a população de BRAPL. A maior população ocorreu em solo desnudo, sendo esta aproximadamente cem vezes superior à população de plantas verificada com o maior nível de palha. Na cobertura original de A. strigosa sobre o solo (2,6 t/ha), verificou-se redução da população de BRAPL em $80 \%$, comparando-se com a população do solo desnudo (Figura 1).

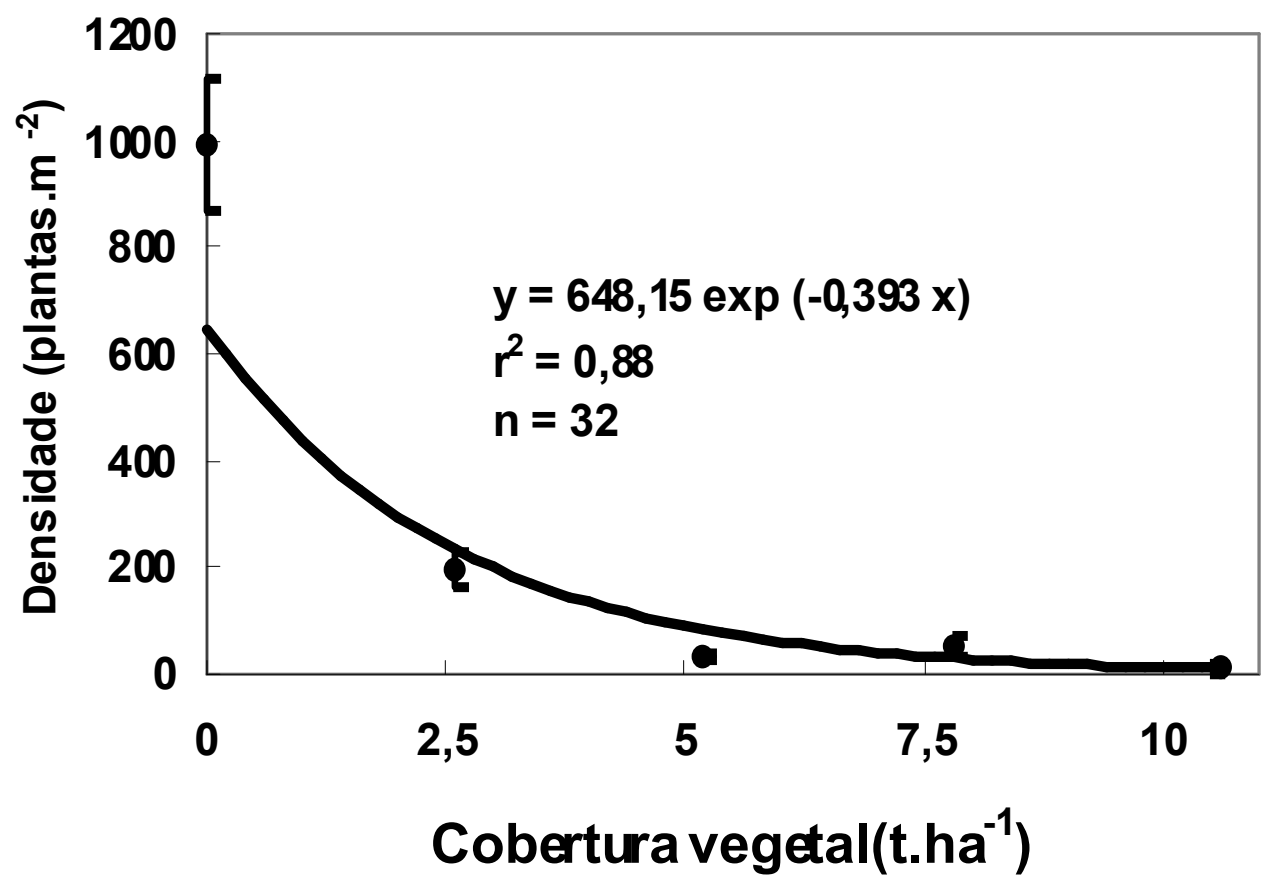

FIGURA 1. Efeito da cobertura vegetal sobre o solo na densidade de Brachiaria plantaginea, na média de oito épocas de avaliação. EEA/UFRGS, Eldorado do Sul, RS, 1997. (Barras verticais indicam o erro padrão da média). 
A equação exponencial foi a que melhor representou a variação da população de BRAPL em resposta aos níveis de cobertura vegetal na superfície do solo (Figura 1). Extrapolando-se além do nível de cobertura testado experimentalmente, calculou-se que seriam necessárias 16,4 t/ha de palha sobre a superfície do solo para que a população de BRAPL fosse uma planta $/ \mathrm{m}^{2}$. Embora seja difícil atingir tal nível de palha em áreas cultivadas, deve-se considerar que o banco de sementes da área experimental era elevado $\left(>34.700 / \mathrm{m}^{2}\right)$ e, em locais onde este for menor, provavelmente com menores quantidades de cobertura vegetal se atinja aquela densidade de BRAPL.

Os resultados encontrados neste experimento confirmam a hipótese de que níveis crescentes de resíduos vegetais sobre o solo reduzem a população de BRAPL. Destaca-se que a redução da população em mais de $95 \%$, constatada com 5,2 t/ha de cobertura, em comparação ao solo desnudo. Este resultado é interessante do ponto de vista agronômico, principalmente considerando que em sistemas de semeadura direta este nível pode ser alcançado com práticas de manejo adequadas. Assim, a manutenção de grande quantidade de palha sobre o solo apresenta pelo menos quatro benefícios ao agricultor: proteção do solo contra a erosão (Rüedell, 1995), otimização da fertilidade (Schoenau \& Campbell, 1996), aumento da população da micro e da mesofauna (Meed et al., 1984; Kremer \& Spencer, 1989) e redução da população de plantas daninhas (Theisen, 1998).

Com relação aos fluxos de germinação e mortalidade de BRAPL, observou-se que, no período de 14 a 97 dias após o manejo da cobertura do solo, a população decresceu de 38 a $68 \%$ para níveis de palha de 7,8 e 10,5 t/ha, respectivamente (Tabela 2). Aplicando-se curvas de regressão aos dados para cada nível de cobertura vegetal, constatou-se que quando esta foi superior a $5,2 \mathrm{t} / \mathrm{ha}$, a população de BRAPL variou de forma exponencial com o aumento da cobertura vegetal sobre o solo (Tabela 3). Todavia, para solo desnudo, a população variou de forma cúbica, enquanto para o nível de palha de $2,6 \mathrm{t} / \mathrm{ha}$ variou conforme o modelo normal (Tabela 3).

TABELA 3. Equações representativas da população de Brachiaria plantaginea, de 14 a 97 DAT $^{1}$, em cinco níveis de cobertura vegetal sobre o solo. EEA/UFRGS, Eldorado do Sul, RS, 1997.

\begin{tabular}{rrrrrrl}
\hline Palha & Equação & \multicolumn{4}{c}{ Parâmetros } & $\mathrm{r}^{2}$ \\
\cline { 3 - 6 } (t/ha) & de regressão & $\mathrm{a}$ & $\mathrm{b}$ & $\mathrm{c}$ & $\mathrm{d}$ & \\
\hline 0,0 & $\mathrm{Y}=\mathrm{a}-\mathrm{bx}+\mathrm{cx}^{2}-\mathrm{dx}^{3}$ & 2024,18 & 52,606 & 0,8659 & 0,0004874 & 0,94 \\
2,6 & $\mathrm{Y}=\mathrm{a} \operatorname{Exp}\left(\left(-(\mathrm{x}-\mathrm{b})^{2}\right) / \mathrm{c}^{2}\right)$ & 255,04 & 42,756 & 46,36 & & 0,70 \\
5,2 & $\mathrm{Y}=\mathrm{a} \operatorname{Exp}-(-\mathrm{b} / \mathrm{x})$ & 22,65 & 13,229 & & & 0,79 \\
7,8 & $\mathrm{Y}=\mathrm{a} \operatorname{Exp}-(-\mathrm{b} / \mathrm{x})$ & 44,07 & 7,150 & & 0,53 \\
10,5 & $\mathrm{Y}=\mathrm{a} \operatorname{Exp}-(-\mathrm{b} / \mathrm{x})$ & 6,66 & 17,059 & 0,85 \\
\hline
\end{tabular}

${ }^{1}$ Dias após o manejo da palha sobre o solo.

Observam-se diversos picos de emergência de BRAPL, durante o período de avaliação (Tabela 2). Em solo desnudo, a maior população ocorreu aos $14 \mathrm{DAP}$, diminuindo até 55 DAP, quando se constatou novo fluxo de emergência. Para solo com 2,6 t/ha de palha à superfície, o maior fluxo de emergência ocorreu de 27 a 48 DAT. Com níveis acima de 5,2 t/ha de palha sobre solo, o maior número de plantas ocorreu até 14 DAP, com novo incremento aos 48

\section{DAP (Tabela 2).}

Do ponto de vista ecológico, o padrão de emergência de BRAPL é do tipo contínuo (Radosevich et al., 1997), percebendo-se, em todos os tratamentos, pelo menos dois fluxos de germinação na estação de crescimento. Vários fatores regulam esse modelo de emergência, como mecanismos de dormência, polimorfismo das 
sementes e condições ambientais (Radosevich et al., 1997). Assim, a heterogeneidade, tanto ambiental quanto intrínseca às sementes, afeta 0 fluxo de germinação de BRAPL.

$\mathrm{O}$ modelo de emergência contínua das sementes tem implicações no manejo quando ocorrente em áreas cultivadas. Dentre estas, destaca-se a dificuldade de manter a área isenta da invasora, pois fluxos tardios de germinação geralmente não são controlados, produzindo sementes e garantindo a perpetuação da espécie para os anos seguintes. Especula-se que esta estratégia, aliada à dormência das sementes do solo, tem garantido a presença constante de diversas espécies daninhas, dentre as quais BRAPL, nas áreas agrícolas.

Embora seja impossível descrever as causas exatas da mortalidade de plantas, pode-se examinar as épocas de maior ocorrência e correlacioná-las com eventos particulares de manejo ou clima, ou com períodos em que a competição foi intensa. Especula-se que grande parte de plântulas morreram por eventos densidade-dependentes (Cousens \& Mortimer, 1995), como ocorre na competição das plantas por recursos do ambiente. De fato, constatou-se que nos tratamentos com maior densidade, a população sofreu auto-ajuste (Tabela 2). Supõe-se que as plantas que emergiram mais cedo, provindas de sementes vigorosas ou que germinaram próximo da superfície levaram vantagem competitiva em relação às demais, explorando antecipadamente e em maior quantidade os recursos oferecidos pelo ambiente.

Considerando-se as plantas adultas, constatou-se aumento exponencial na produção de matéria seca por planta à medida que se incrementou a cobertura vegetal sobre o solo (Figura 2). Esse aumento é decorrente do menor número de plantas por área nesta condição (Figura 1).

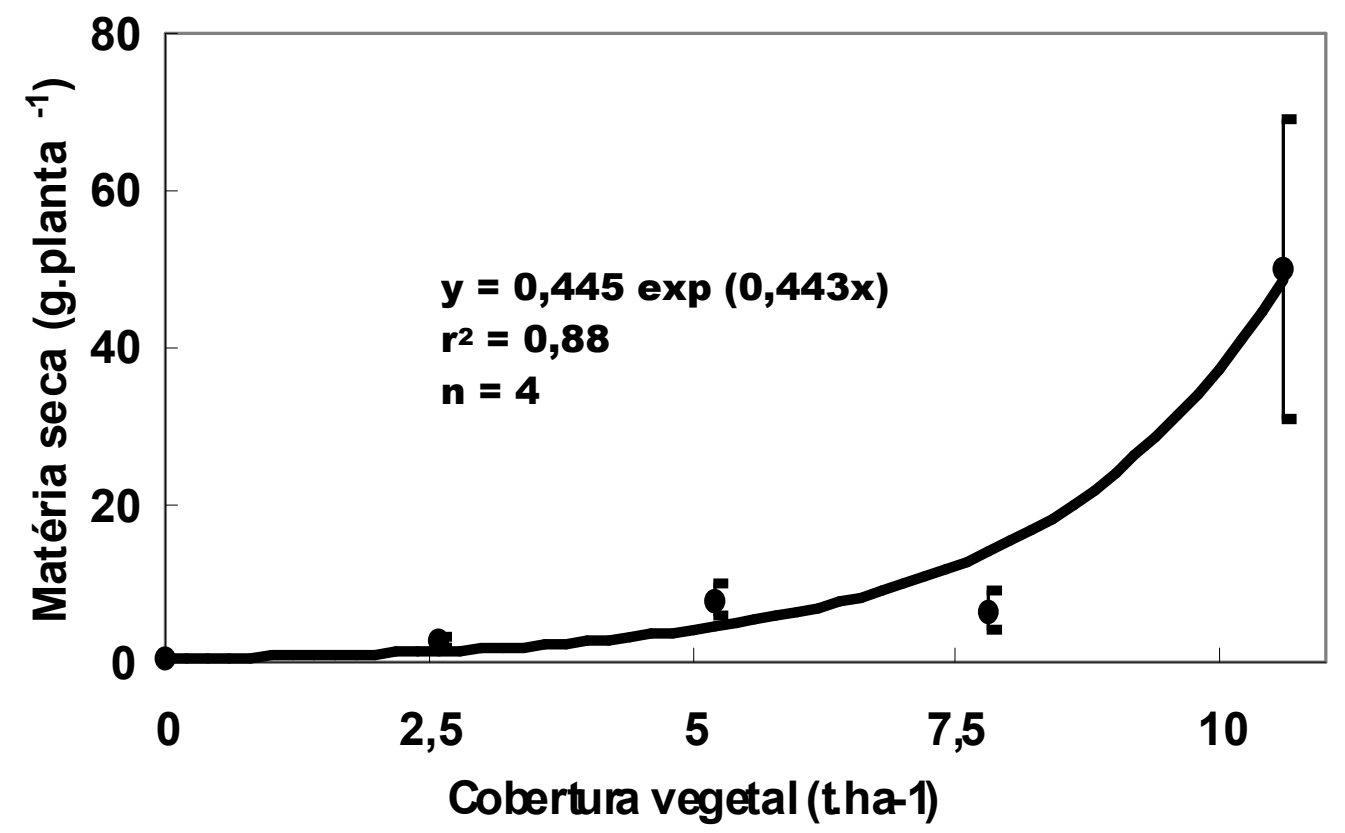

FIGURA 2. Efeito da cobertura vegetal sobre o solo na matéria seca por planta de Brachiaria plantaginea, aos 97 dias após o manejo da palha. EEA/UFRGS, Eldorado do Sul, RS, 1997. (Barras verticais indicam o erro padrão da média). 
A relação negativa entre a densidade de plantas (Figura 1) e o peso por planta (Figura 2) demonstra a plasticidade de BRAPL, a qual alterou seu tamanho e biomassa em resposta ao estresse causado pela alta densidade. Constatou-se incremento próximo a 190 vezes no peso individual, comparando-se as plantas em solo desnudo com aquelas crescendo sob alta quantidade de resíduos vegetais (Figura 2). Dessa forma, as plantas que cresceram em altos níveis de cobertura do solo atingiram sucesso no seu estabelecimento, pois receberam, proporcionalmente, alta quantidade de recursos do ambiente, como água, nutrientes e luz, não se observando efeito dos tratamentos de palha na biomassa de BRAPL por área, cuja produção média de matéria seca foi $1174 \mathrm{~kg} / \mathrm{ha}$. Supõe-se que isto tenha ocorrido devido ao fenômeno conhecido como "Lei do rendimento final constante" (Altieri \& Liebman, 1988), a qual estabelece que a produção é proporcional aos recursos disponíveis no ambiente, independentemente da densidade de plantas.

\section{Agradecimentos}

Agradecemos às sugestões dos professores Nilson G. Fleck, Paulo R. F. da Silva e Ênio Marchezan, ao apoio dos estudantes Cléo M. Carollo e Eduardo A. Manjabosco e auxílio financeiro do CAPES, CNPq (processo 520057/96-1) e FAPERGS (95.00901-2).

\section{LITERATURA CITADA}

ALMEIDA, F. S. Controle de plantas daninhas em plantio direto. Londrina: IAPAR, 1991. 34p. (Circular Técnica)

ALTIERI, M. A.; LIEBMAN, M. Weed Management in Agroecosystems: Ecological Approaches. Boca Raton: CRC Press, 1988. 354 p.

BIANCHI, M. A. Programa de difusão do manejo integrado de plantas daninhas em soja. In: REUNIÃO DE PESQUISA DE SOJA DA REGIÃO SUL, 23., Porto Alegre, RS. Ata e Resumos. Porto Alegre:Departamento de Plantas de Lavoura da UFRGS, 1996. p.125.

BRAGAGNOLO, N.; MIELNICZUK, J. Cobertura do solo por palha de trigo e seu relacionamento com a temperatura $\mathrm{e}$ umidade do solo. Rev. Bras. Ciên. Solo, v.14, n.2, p.369-374, 1990.

BUHLER, D. D.; OPLINGER, E. S. Influence of tillage systems on annual weed densities and control in solid-seeded soybean (Glycine max). Weed Sci., v. 38, n. 1, p. 158-165, 1990.

CAROLLO, C. M.; THEISEN, G.; VIDAL, R. A. et al. Germinação de leiteira (Euphorbia heterophylla) e papuã (Brachiaria plantaginea) submetidos a diferentes tratamentos de temperatura. In: SALÃO DE INICIAÇÃO CIENTÍFICA, 9, 1997, Porto Alegre, RS. Livro de Resumos. Porto Alegre: UFRGS/PROPESQ, 1997. p. 99.

COUSENS, R.; MORTIMER, M. Dynamics of weed populations. Cambridge: Cambridge University Press, 1995. 328 p.

ESPIRITO SANTO, F. R. C. Distribuição de óxidos de $\mathrm{Fe}$ em uma catena de solos derivados de granito da região fisiográfica da Depressão Central do estado do Rio Grande do Sul. Porto Alegre, 1988. 141 f. Dissertação (Mestrado em Agronomia-Solos) - Programa de PósGraduação em Agronomia, Universidade Federal do Rio Grande do Sul, Porto Alegre, 1988.

FERNANDEZ-QUINTANILLA, C. Studying the population dynamics of weeds. Weed Res., Oxford, v. 28, n. 4, p. 443-447, 1988. 
FLECK, N. G. Interferência de papuã (Brachiaria plantaginea) com soja e ganho de produtividade obtido através do seu controle. Pesquisa Agropecuária Gaúcha, v.2, n.1, p.63-68, 1996.

KISSMANN, K. G. Plantas Infestantes e Nocivas. São Paulo: BASF, 1991. v.1, 603 p.

KREMER, R. J. Integration of biological methods for weed management. WSSA Abstracts, v.38, p. 46, 1998.

KREMER, R. J.; SPENCER, N. R. Impact of a seed-feeding insect and microorganisms on velvetleaf (Abutilon theophrasti) seed viability. Weed Sci., v. 37, n. 2, p. 211-216, 1989.

MEED, R. W.; NIKANDROW, A.; JONES, K. Possible use of soil-born pathogen for weed control. In: INTERNATIONAL SYMPOSIUM OF BIOLOGIC CONTROL OF WEEDS, 6.,1994, Vancouver. Proceedings... Vancouver: [s.n.], 1984. p. 19-25.

PUTNAM, A. R.; DEFRANK, J.; BARNES, J. P. Explotation of allelopathy for weed control in annual and perennial cropping systems. J. Chem. Ecol., v. 9, n.8, p. 1001-1010, 1983.

RADOSEVICH, S. R.; HOLT, J. S.; GHERSA, C. Weed ecology: implications for vegetation management. 2 ed. New York: Wiley, 1997. $588 \mathrm{p}$.

RÜEDELL, J. Plantio direto na região de Cruz Alta. Cruz Alta: FUNDACEP/BASF, 1995. $134 \mathrm{p}$.

SALTON, J. C.; MIELNICZUK, J. Relações entre sistemas de preparo, temperatura e umidade de um podzólico vermelho escuro de Eldorado do Sul (RS). Revista Brasileira de Ciência do Solo, v.19, n.2, p.313-319, 1995.

SCHOENAU, J. J.; CAMPBELL, C. A. Impact of crop residues on nutrient availability in conservation tillage systems. Can. J. Plant Sci., v.76, n.4, p.621-626, 1996.

THEISEN, G. Influência de palha de aveia preta em papuã (Brachiaria plantaginea (Link) Hithc.) e seu impacto em soja. Porto Alegre: Faculdade de Agronomia da UFRGS, 1998. 87 f. Tese (Mestrado em Agronomia), FA/UFRGS, Porto Alegre, 1998.

VIDAL, R. A. Amount of crop residues in notill farming affects weed-crop ecosystems. West Lafayette: Purdue University, 1995. 162 f. Tese (Doutorado), Purdue University, West Lafayette, 1995.

ZULLO JR., J.; ARRUDA, F. B. Programa computacional para ajuste de equações em dados experimentais. Campinas: Instituto Agronômico, 1986. 23p. (Boletim Técnico, 113). 